\title{
Diving into Lake Devo: Modes of Representation and Means of Interaction and Reflection in Online Role-Play
}
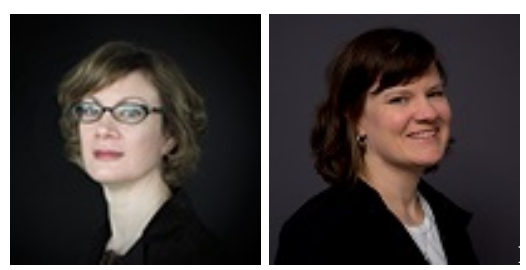

Linda Koechli and Maureen Glynn Ryerson University, Canada

\section{Abstract}

This paper outlines an action research project involving the development of an educational online role-playing website, known as Lake Devo. Designed in keeping with constructivist principles, the website is used in select post-secondary courses at Ryerson University and allows learners to work synchronously, using visual, audio, and text elements to create avatars and interact in online role-play scenarios. The website also provides an integrated area for debrief following role-play activities. The features of the website were deliberately intended to provide a viable alternative to text-only online role-play activities, while not requiring the highly sophisticated elements of 3D virtual environments. During the period of the project on which this article reports, learners were invited to use the Lake Devo website for an assigned role-play activity. Online learner survey responses were collected following the pilot implementations of the website to determine the extent to which the non-text modes of representation (visual, audio) in Lake Devo, along with an integrated debrief area on the site, supported the learners in their online role-play activity. The preliminary findings suggest that Lake Devo provides an environment that effectively supports online role-play. The simple format of the Lake Devo avatars, the availability of visual and audio elements, and the ability to create a lasting artifact for review in a dedicated debrief area engage students and also reinforce the constructivist and collaborative nature of role-play activities. For practitioners beyond the Lake Devo project team and the Ryerson context, the Lake Devo website provides an example of an online role-play environment that offers alternatives to text-based and/ or 3D virtual worlds.

Keywords: Online role play; avatars; constructivist learning; collaborative learning 


\section{Introduction}

Over the past decade, educators have increasingly adopted role-play as an online pedagogical strategy in a number of contexts, including instructor training (Bell, 2001), international relations (Vincent \& Shepherd, 1998), nursing (Nelson \& Blenkin, 2007; Levitt \&Adelman, 2010), and management (J ones, 2007; Liebowitz, 2003). Online roleplay, as distinct from simulations or games, appears to be of particular value when learners are required to develop skills in interpersonal interaction (Feinstein et al., 2002; Russell \&Shepherd, 2010).

The course used for this pilot study is an interdisciplinary course in "Conflict Resolution and Dispute Negotiation" (CINT905), offered by the Community Services Program Area at The G. Raymond Chang School of Continuing Education, Ryerson University. The course incorporates role-play as a teaching strategy in order to give learners the opportunity to practice communication and interpersonal skills within the context of a hypothetical face-to-face conversation. The instructor of the online offering of this course had originally conducted the role-play exercise using the Blackboard learning management system's (LMS) discussion forum, similar to an approach described by Bender (2005). While the instructor reported that the text-based activity was effective in meeting learning objectives, she identified a need to improve the ease-of-use of the roleplay, and expressed a desire to explore other modes of representation to increase learner engagement. Beyond the needs of this particular course, many other Ryerson instructors from a variety of subject areas had previously demonstrated an interest in online role-play, but had failed to incorporate it into their online course design. This may have been due to a range of factors, including the overall limitations of the LMS to facilitate implementation of constructivist strategies such as role-play (Lane, 2008). In addition, many instructors lacked the familiarity with other possible tools such as 3D virtual worlds and, as suggested in studies from other institutions, could not commit the time required to integrate such tools into their teaching (Moser, 2007).

The instructor of CINT905 turned to The Chang School's Digital Education Strategies (DES) unit for assistance. The DES unit is a multi-disciplinary team of instructional designers, web developers, and editors who support online course development for The Chang School. The DES team works in a collaborative way with instructors and subject matter experts and brings a predominantly constructivist approach to its educational developments. Given the situation described above, the DES team saw the potential for an online learning environment that would provide an engaging experience using alternate modes of representation, and also offer a pedagogical framework that would encourage increased adoption of online role-play activities in general. As such, the team undertook the project to develop an online role-play website that would come to be named Lake Devo. The Lake Devo website was designed to provide an infrastructure for online role-play activities, while allowing for flexibility so that it could be used across disciplines, as well as in multiple delivery formats (e.g., fully online, hybrid, classroom). Given that the Lake Devo website is a unique offering in the area of educational online 
role-play, this study explores student response to some of the specific features of the site which distinguish it from other online role-play environments.

\section{Background}

Before settling on the required features for the Lake Devo website, the project team undertook a thorough literature review and investigation of existing practices for online role-play and, in particular, the types of online environments in which these learning activities take place. The findings are summarized here to provide background for the study.

Studies of educational online role-playing describe the use of environments that fall largely into two categories: text-based environments and 3D virtual worlds. Text-based approaches to online role-play typically employ an asynchronous email and discussion board (Freeman \& Capper, 1998; Bell, 2001), synchronous chat (Liebowitz, 2003; Phillips, 2005), or a combination of these types of tools, which may be offered through an LMS (Vincent \& Shepherd, 1998; McLaughlin \& Kirkpatrick, 2004; Bender, 2005; Cornelius, Gordon, \& Harris, 2011) or other custom created text-based systems, such as The Forum (Kinder, Fardon, \& Yasmeen, 1999) or ICONS (Vavrina, 1992; Kaufman, 1998; Starkey \& Blake, 2001). One common characteristic of text-based role-play environments is the minimal learning curve for the learners, as well as the instructor, due to existing familiarity with these types of tools (Bender, 2005). In some cases, a customized role-play environment, or virtual situated learning environment (J ones, 2007), also integrates various pre-fabricated media elements such as photos, maps, and videos to help create the sense of a 2D simulated world; examples include Fablusi (Ip, Linser, \& Naidu, 2001; Nelson \& Blenkin, 2007), and SIMPLE (Barton, McKellar, \& Maharg, 2007; Hughes et al., 2008). While media elements are incorporated into these environments, they are typically used for reference and the primary mode of learner interaction remains anchored in text. Some studies have been done regarding the use of 2D "graphical chat" tools (Ingram, Hathorn, \& Evans, 2000), but not directly in relation to their support of online role-play.

In addition to text-based environments, online role-play also takes place in 3D virtual environments, which employ sophisticated graphics, allowing learners to represent themselves as avatars in simulated worlds (Gao, Noh, \& Koehler, 2009; Morse et al., 2009; Dhaliwal et al., 2007; J amaludin, Chee, \& Ho, 2009). Communication occurs in real time, typically through text chat, animated gestures, movement, and possibly voice. These virtual worlds are engaging, media rich, and include a variety of modes of representation. However, as learning environments they pose several challenges. Dudeney and Ramsay (2009) describe how the learner may become quickly overwhelmed and discouraged by what is known as the "First Hour," due to the initial high learning curve. Even after learners have become familiar with a virtual world's environment, challenges may still exist in navigating the user interface, which can be complex and unintuitive (Dudeney \& Ramsay, 2009). Furthermore, for instructors, 
ensuring that role-play activities work well in the "free format learning experience" (Kluge \& Riley, 2008, p. 132) of virtual worlds can be challenging and time consuming. Some studies have indicated that when using 3D virtual worlds for educational purposes, instructors need to ensure that the virtual environment offers enough variety in terms of scenes and objects so that learners do not get bored and frustrated (Finkelstein, 2006); however, at the same time, the environment should not be so appealing as to distract learners from the learning activity (Kluge \& Riley, 2008).

Following a review of the types of environments summarized above, the Lake Devo project team turned their attention to considering these environments in the context of a constructivist approach to learning.

\section{Constructivist Context for Development of Online Role-Playing Environments}

Role-play, whether online or in-person, has been acknowledged as a constructivist activity (Wills \& MacDougall, 2009), because it employs a learner-centred, experiential and collaborative approach, and incorporates reflective processes as a key strategy (Van Ments, 1999). The online role-play environments discussed in the preceding literature review support many of the goals of a constructivist approach as outlined by Honebein (1996). The following list summarizes these goals.

Goals for the Design of Constructivist Learning Environments

1. Provide experience with the knowledge construction process.

2. Provide experience in and appreciation for multiple perspectives.

3. Embed learning in realistic and relevant contexts.

4. Encourage ownership and voice in the learning process.

5. Embed learning in social experience.

6. Encourage the use of multiple modes of representation.

7. Encourage self-awareness of the knowledge construction process.

All of the environments reviewed by the Lake Devo project team have learners assume a role and interact with other role-players online. This capability encourages participation in the knowledge construction process and provides exposure to multiple perspectives (Goals 1 and 2). Since the majority of environments allow instructors to provide learners with real-world scenarios, the activities tend to take place within realistic and relevant contexts (Goal 3). Because the instructor often acts as facilitator or moderator and the activities require active participation by all group members, the role-plays are highly collaborative and social forms of learning (Goals 4 and 5). However, with regard to 
supporting Goal 6 (the use of multiple modes of representation, e.g., text, graphics, audio) and Goal 7 (encouragement of the self-awareness of the knowledge construction process) the literature reveals some important issues, discussed in detail below, which helped to underpin planning for the Lake Devo project.

\section{Encouraging Use of Multiple Modes of Representation}

As mentioned, the use of multiple modes of representation is a key element of constructivist learning activities such as role-play. Honebein (1996) promotes adoption of additional media such as video and sound to provide richer learning experiences. The environments identified in the literature review represent two extremes with respect to modes of representation-from limited integration of additional media to the use of highly sophisticated multimedia elements. The Lake Devo project team sought to develop an environment that fell somewhere between these two extremes, due to the findings summarized in the following three paragraphs.

Some studies state that traditional online communication tools are poor at supporting interpersonal communication-the development of which is often a key learning objective of role-play activity-because of the limited channels for verbal, aural, and non-verbal cues (Redfern \& Naughton, 2002). For example, in the text-based tools described above, visible embodiments of the learners' roles, audible sound, and detectable movement tend to be absent. In a few cases, learners compensated for the lack of visual, verbal, and non-verbal cues by including text descriptions of them (e.g., "Ring, Ring, Ring," “breaks down in tears”) (Bender, 2005; Nelson \& Blenkin, 2007). Although the researchers report that such compensatory measures adequately communicated emotions and attitudes, the absence of multiple modes of representation is not explored.

By contrast, studies in a higher education context that use 3D virtual environments, where visual embodiments of learners' roles are possible (e.g., avatars), have found that realistic visual representations contribute to a feeling of social presence and ultimately a higher level of satisfaction with the learning experience compared to text-only environments (Annetta, Klesath, \& Holmes, 2008; Warburton, 2009; Dhaliwal et al., 2007; J amaludin et al., 2009). Notwithstanding this improved sense of social presence, some virtual environments may present challenges of a different nature. Morse et al. (2009), in their study of role-play within Second Life, report that learners derived minimal useful visual data from their own avatar or the avatars of other learners. As a result, learners often misinterpreted gestures and physical positioning of the avatars. Other studies found that avatar's facial expressions in 3D virtual worlds are limited (Peterson, 2006; Bronack et al., 2008) -so much so that learners have resorted to the use of emoticons within the text-based environment of the virtual world's chat tool (Peterson et al., 2007; Bronack et al., 2008). 
Further to the findings cited above, it has been argued by some researchers that a high degree of sophistication of visuals, such as 3D avatars, may not be necessary in virtual learning environments (Fabri, Moore, \& Hobbs, 2004; Cornelius, Gordon, \& Harris, 2011); rather, it is the customization of visuals that is essential (Linser \& Ip, 2005, as quoted by Russell \& Shepherd, 2010; Robbins-Bell, 2008). Still, detailed studies examining the addition of more simplistic, customizable avatars to supplement text in educational online role-play are lacking. Also lacking are studies regarding the use of sound within virtual worlds as an additional mode of representation in online role-play.

Based on this review, the Lake Devo project team resolved to experiment with offering multiple modes of representation in support of online role-play using tools that would be simple to manipulate.

\section{Self-Awareness of the Knowledge Construction Process}

Honebien (1996) explains that "knowing how we know" (p. 12) is an important outcome of constructivist learning. This requires the creation of opportunities for students to analyze their own construction of knowledge. In the context of role-play activities, this opportunity often takes the form of a debrief. Van Ments (1999) states that debriefing is the most important part of the role-play activity, as it is at this point that behaviours are corrected, lessons are learned, and other possible solutions and outcomes are highlighted. The environments used for role-play activities that take place fully online should support debriefing out of role, within the larger class community (Russell \& Shepherd, 2010). While most studies mentioned above acknowledge the importance of the debriefing session, many omit details pertaining to how it is conducted. Some solutions mentioned in the studies comprise a blended approach, incorporating some face-to-face interactions (Bell 2001; McLaughlin \& Kirkpatrick, 2004; Hrastinski \& Watson, 2009). Among the studies that do provide details are some that indicate that group members' experiences of the online role-play form the basis of the debrief (Vincent \& Shepherd, 1998; Phillips, 2005; Nelson \& Blenkin, 2007). In other cases, the entire class attends a live online role-play session or follows an asynchronous discussion board thread and observes as the role-play unfolds (Liebowitz, 2003; Bender, 2005).

Of particular note are the studies indicating that artifacts (lasting, retrievable, and accurate records) of the online role-plays are used for a debrief (Bender, 2005). In studying games, simulations, and virtual worlds, Aldrich (2009) states that using an artifact is advantageous because if the activity cannot be witnessed by others in real time then the artifact can be viewed and shared at a later date. In addition to providing a way to retrieve a learner's or group's work well beyond the activity, the artifact could be considered a type of learner presentation and may therefore also reinforce the feeling of learner ownership. Lastly, it can serve as the basis of assessment (Aldrich, 2009). In those studies of online role-play which indicate the use of some sort of artifact, it appears most often in the form of a chat transcript, which is distributed among all class members (Bender, 2005). 
Beyond the text-based artifact (such as a chat transcript) is the notion, described by Miao et al. (2000), of a "visually structured knowledge representation method" that provides learners the opportunity to "build a coherent representation of their common knowledge" (p. 306). This visual representation functions as a "group memory" and allowing learners access to it gives them the opportunity to "negotiate and explore the information in the shared artifact" (Miao et al., 2000). Miao et al. (2000) specifically examine the use of shared artifacts for the presentation of complex online problembased research and learning. Where online role-play is concerned, the concept of a visual shared artifact is mostly absent, aside from the labour-intensive possibility in virtual worlds of media elements manually added to the chat transcript (e.g., screen shots, videos) (Morse et al., 2009). A visual shared artifact as an integrated element of a given role-play tool does not appear to be currently or easily available. Furthermore, none of the existing studies of online role-play tools describe in detail how an artifact might engage learners, be easily sharable among all peers, or be combined with a discussion space for peer exchange and reflection.

In summary, the Lake Devo team observed through their review of the literature, that an environment which allowed for multiple modes of representation, along with an integrated debrief area incorporating a visual artifact, might support online role-play in a manner not yet offered in existing online role-play environments.

\section{Focus of this Study}

Given the request presented by the instructor, and the findings of the Lake Devo team's review of online role-play environments, the project team set out to develop an environment that offered a middle ground between text-only online role-play environments and highly complex 3D virtual environments. They deliberately chose not to design a fully realistic world in which to interact, but rather an environment for roleplay dialogue that would offer added channels of expression to support interpersonal communication, as well as an integrated debrief area. With these goals in mind, the project team identified the following enquiries as their focus when conducting an assessment of the Lake Devo pilot.

Do the following elements, which are present in the Lake Devo website, support and engage learners in online role-play activity in a manner not offered in text-only or 3D virtual environments?

- Simple visual and audio modes of representation such as avatars, background images, and sound effects

- An integrated debrief area that includes a shareable, multimedia artifact and forum for discussion

A brief description of the Lake Devo role-play environment is provided below to provide additional context for the study. 


\section{Lake Devo Description}

Lake Devo is a web-based application, accessible at lakedevo.ryerson.ca, used by Ryerson University instructors to support online role-play assignments, which typically include identified learning outcomes associated with interpersonal communication and negotiation skills. The site affords learners the ability to undertake preparatory work asynchronously prior to interacting synchronously for the purposes of the role-play activity. Once the role-play activity is complete, the proceedings of the role-play may be published in the form of a presentation, or artifact, referred to in Lake Devo as a movie (see Figure 1). (Note: The site has been upgraded since the time of this study and, when accessed with the above link, will appear differently from the screen shots below.)

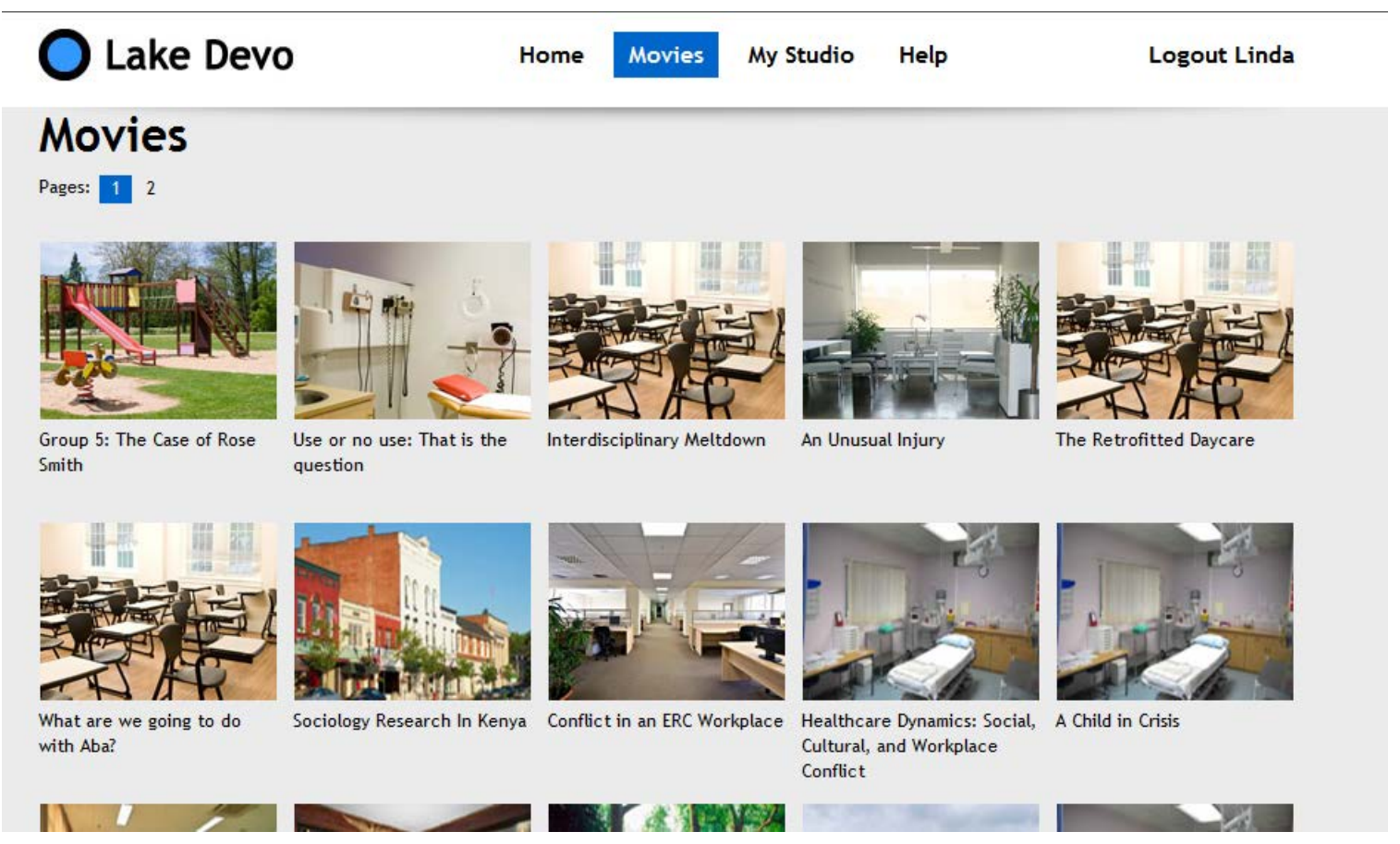

Figure 1. Screenshot of the Lake Devo Movies page.

In order for learners to participate in a role-play exercise, a Lake Devo Community must be created for each cohort. This takes place when class lists are provided by instructors to the Lake Devo team at DES for entry in the Lake Devo database. Once a class is entered into the database as a Community, the learners are organized into role-play groups (either randomized or instructor-specified) and a group leader is identified. Learners are issued passwords to access their project in the role-play environment.

Before the live role-play activity, each group member creates a visual representation, or avatar, of his or her role-play character using the Character Creation tool, which allows customization in form (see Figure 2). Learners make selections from a menu of physical attributes such as skin tone, hair colour and style, clothing colour, and facial features. 
Also before the live role-play, group leaders set up background scenes (choosing from a library of images) in which the role-play will take place. For characters and scenes, names and descriptions can be added to provide context.

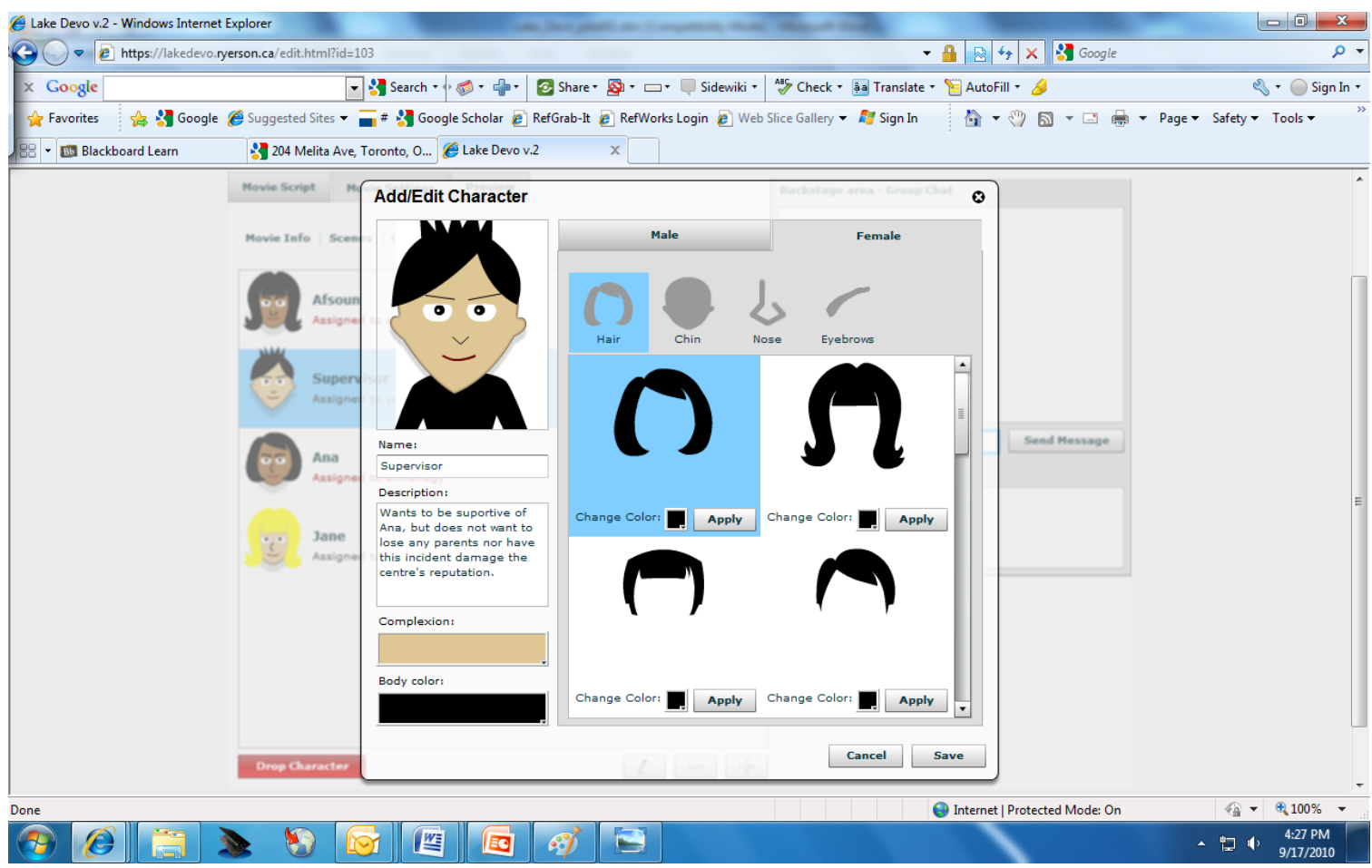

Figure 2. Screenshot of the Lake Devo Character Creation tool.

Once avatars have been created, the group must agree on a time to meet live online to role-play synchronously. The group members participate as their avatars in a spontaneous dialogue, which forms a "script." Learners see their fellow role-players posting in real time (Figure 3). To enhance participants' ability to express emotions, graphics representing facial expressions can be selected with each dialogue entry (Figure 4). Text during the scripting can be entered as speech, thought, or action. Learners may select sounds (such as coughing, whistling, laughter, footsteps, a doorbell, a phone ringing, etc.) to insert in the script from a built-in library. The sound effects are divided into menus of character generated and ambient sounds. All group members are able to see and hear these additional audio elements, when they are inserted into the dialogue by an individual member during the live role-play. In addition, a Backstage Group Chat area assists learners in planning the role-play and discussing logistics as the role-play unfolds. 


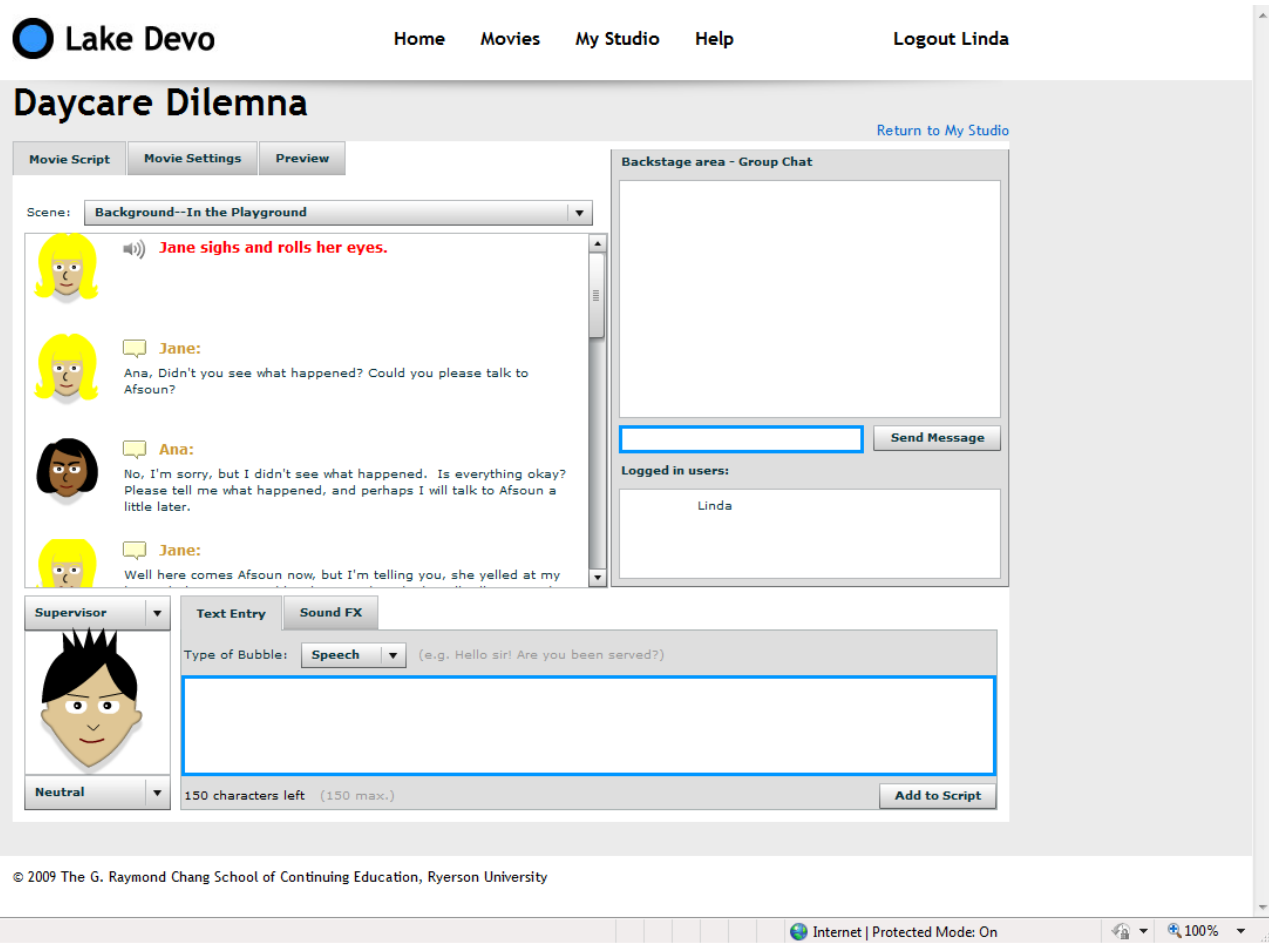

Figure 3. Screenshot of the Lake Devo Script Building tool.

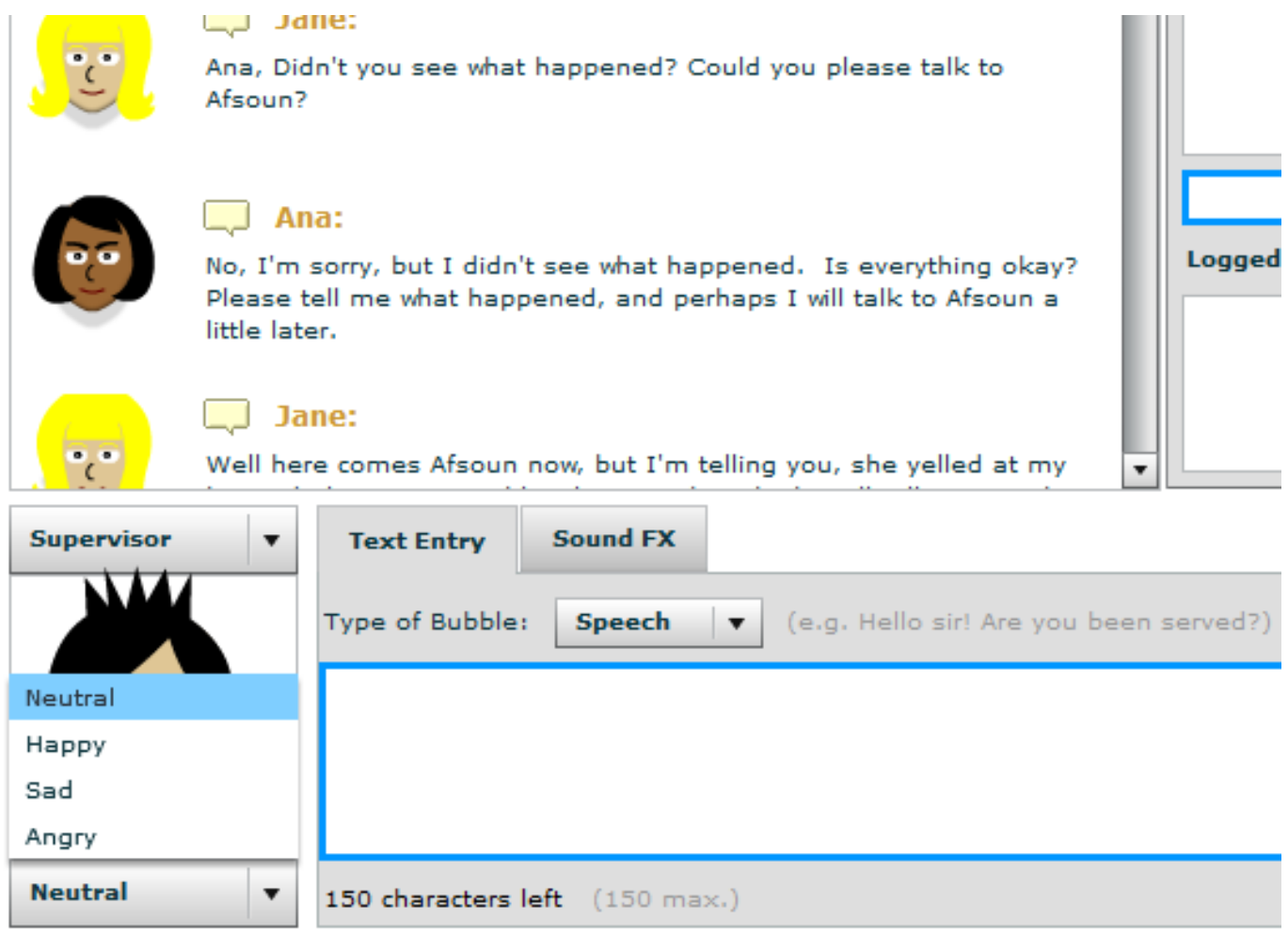

Figure 4. Screenshot of the Lake Devo Emotional Expression Selector tool. 
The role-play dialogue is automatically saved, but each learner may edit his or her character's dialogue after the live role-play activity. Once a group has finalized their role-play, they publish it to their Lake Devo Community list in the form of a 2D narrative movie. Because members of the community can easily view role-play movies, the movie format allows all to participate in the debriefing, which occurs in a discussion area below each movie (Figure 5).

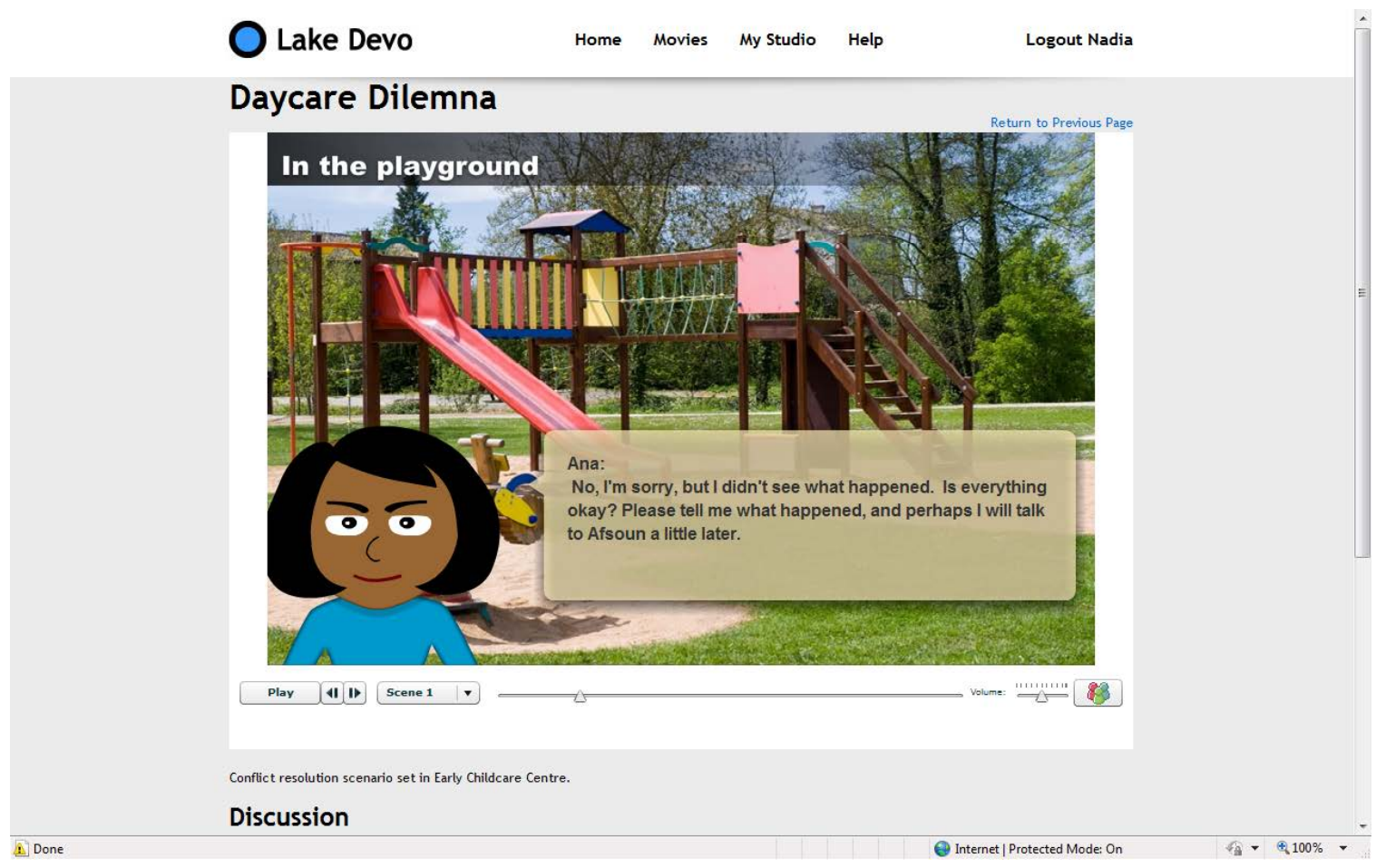

Conflict resolution scenario set in Early Childcare Centre.

\section{Discussion}

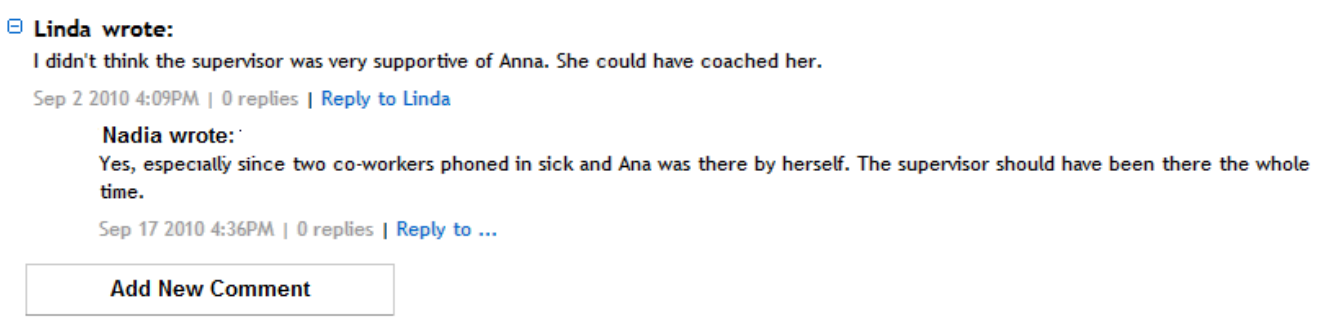

Figure 5. Screenshot of the Lake Devo Role-play Debrief area. 


\section{Method}

An action research methodology was taken when creating Lake Devo, as well as when analyzing the results of the pilot project. Given its collaborative and participatory nature, this methodology aligned well with the constructivist approach of the team. The project team moved ahead with their development of the Lake Devo website with, what Kember (1998) phrases as "an avowed intention of improving their practice," through trial, evaluation, and refinement (p. 53).

Lomax (2007) defines action research as action for improvement, done by oneself, on one's own practice, democratically, to generate theory, in a critical, iterative manner. Lomax (2007) further specifies that action research should be validated by peers and presented for consideration to other professionals, policymakers, users, and academics. In keeping with these characteristics, the Lake Devo project team sought to improve practice at Ryerson in delivering role-play in online learning. The team enlisted input from instructors, students, instructional designers, and web developers on their design for the Lake Devo role-play environment. Upon piloting the use of the Lake Devo website by students, the team developed an online survey to gather feedback on Lake Devo. The study was approved by the Ryerson University Research Ethics Board and the results of the survey are reported here.

As mentioned in the Introduction, the subjects of the study were participants in the online course, "Conflict Resolution and Dispute Negotiation" (CINT905). The participants comprised members of the winter 2010 and winter 2011 fully online offerings of the course through The Chang School at Ryerson. In each of these offerings of the course, the Lake Devo online role-play environment was provided for use for an assigned role-play activity. Once students had completed the online role-play and debrief activities, an announcement was posted on the course homepage inviting learners to participate in the 37 item online questionnaire. The questionnaire included a mix of question types, including a four-point Likert agreement scale, yes or no questions, and open-ended questions. Learners were asked to assess their experience with Lake Devo in the following categories: visualization of character and situational setting; level of involvement in creation and viewing of movies; use of communication tools; and personal satisfaction with the experience. At the end of each category of questions, learners were invited to share further comments. These categories, and the questions associated with them, were formulated to measure the extent to which some of the distinct features of the Lake Devo online role-play environment (i.e., visual and audio elements, an integrated debrief area) supported online role-play activity (see Focus of this Study).

One hundred and sixteen learners were invited to participate. Fifty-four percent $(n=61)$ responded. The majority of the respondents were female (90\%) and the age range, among those under 54 years, was relatively evenly distributed (see Table 1). 
Table 1

Range of Age of Survey Participants

\begin{tabular}{|l|l|}
\hline Age range & Percentage \\
\hline Under 24 years & $38 \%$ \\
\hline 25- 34 years & $27 \%$ \\
\hline $35-54$ years & $31 \%$ \\
\hline Over 50 years & $5 \%$ \\
\hline
\end{tabular}

\section{Results}

\section{Visual Representation}

(Note: Throughout the questionnaire and results, avatars are referred to as characters, in keeping with the nomenclature of the Lake Devo website.)

Overall, elements of visual representation on the Lake Devo website received extremely positive feedback from the pilot groups, as demonstrated below by the results presented in Table 2. On the Likert agreement scale, learners reported that the ability to represent the character visually helped in expression (95\%) and was enjoyable (93\%). There was also high agreement that the use of graphics assisted with the expression of emotion (83\%). Ninety-eight percent agreed that character creation was easy, and the majority liked the look of the character (80\%). A feeling of ownership in creating the character had an $86 \%$ agreement rating. Eighty-eight percent of the learners reported that they identified with the character (see Table 2). 
Table 2

Ease of Visual Representation of Character and Backgrounds

\begin{tabular}{|l|l|l|}
\hline $\begin{array}{l}\text { Students were asked to rate the following } \\
\text { statements: }\end{array}$ & $\begin{array}{l}\text { Agree } \\
\%\end{array}$ & $\begin{array}{l}\text { Disagree } \\
\%\end{array}$ \\
\hline $\begin{array}{l}\text { The graphics for emotional expression helped me } \\
\text { express emotions of my character that would have } \\
\text { been difficult in the online environment. }\end{array}$ & 83 & 17 \\
\hline $\begin{array}{l}\text { Being able to represent my character visually } \\
\text { helped me express aspects such as personality or } \\
\text { physical traits that would have otherwise been } \\
\text { difficult in the online environment. }\end{array}$ & 95 & 5 \\
\hline Creating my own character was enjoyable. & 93 & 7 \\
\hline Creating my own character was easy. & 98 & 2 \\
\hline I like the look of the character I can create. & 80 & 20 \\
\hline $\begin{array}{l}\text { Being able to create a visual representation of my } \\
\text { character helped me identify with the character I } \\
\text { role-played. }\end{array}$ & 88 & 12 \\
\hline $\begin{array}{l}\text { Being able to create a visual representation of my } \\
\text { character gives me a sense of ownership. }\end{array}$ & 86 & 14 \\
\hline $\begin{array}{l}\text { The ability to add backgrounds was important to } \\
\text { me in setting the scene of the conflict scenario. }\end{array}$ & 96 & 4 \\
\hline
\end{tabular}

After rating the statements above, learners were provided with the opportunity to respond to the following request: "Please enter any comments about character creation." Learner comments in this category mentioned the ease of use of the application. In the words of one learner, "I thought creating my own character was an interesting way to represent how I would want the character to look. It was easy."

Another learner commented that the creation of characters and backgrounds was "fun and interactive" and "worth spending the time to figure it out."

The ability to customize visual elements also drew positive comments:

The character creation ... allowed for cultural additions, which was important to our conflict course when dealing with multicultural barriers.

I thought it was really neat that we had the opportunity to make our own characters. It allowed a lot more personalization than I thought possible in an online course.

In their comments, learners identified a need for expanded options among the visual elements of the application. For example, in one learner's words, 
There should be more facial features, clothing, and sound effects available when creating your character. Also, there should be more scene backgrounds; sometimes you are limited to choosing certain visuals that are not $100 \%$ correlated to your character or theme.

Similar feedback included:

A wider choice of character emotions would have been more useful to portray the atmosphere (e.g., surprised, confused).

I felt as though many of the characters in our group looked very similar, therefore a little confusing. It would be nice to have more options for hair, eyes, noses, etc.

My character was of a nurse. There wasn't any specific attire that represented me as a nurse, therefore, I still had to wear the normal casual clothes and specifically had to say I was a nurse in order for the viewers to understand.

\section{Sound Effects}

Again on the Likert scale, there was high agreement with the statement that the ability to add sound effects helped learners express aspects of the character that would have otherwise been difficult in the online environment (87\%). In addition, when asked to rate the importance of using sound effects to set the scene of the conflict, learners valued ambient sound effects (88\%) (see Table 3).

Table 3

\section{Sound Effects}

\begin{tabular}{|l|l|l|}
\hline $\begin{array}{l}\text { Students were asked to rate the following } \\
\text { statements: }\end{array}$ & $\begin{array}{l}\text { Agree } \\
\%\end{array}$ & $\begin{array}{l}\text { Disagree } \\
\%\end{array}$ \\
\hline $\begin{array}{l}\text { The ability to include sound effects produced by my } \\
\text { character helped me to express aspects of the } \\
\text { character that would have been otherwise difficult } \\
\text { in the online environment. }\end{array}$ & 87 & 13 \\
\hline $\begin{array}{l}\text { The ability to include ambient sound effects was } \\
\text { important to me in setting the scene of the conflict } \\
\text { scenario. }\end{array}$ & 88 & 13 \\
\hline
\end{tabular}




\section{Movie Creation and Viewing}

Ratings of statements with respect to learner involvement in movie creation and viewing showed that the majority of the respondents agreed that creating the script was easy (79\%) and enjoyable (84\%). Eighty-eight percent agreed that watching the movies from the other groups helped them understand the conflict scenario (see Table 4).

Table 4

Involvement in Movie Creation and Viewing

\begin{tabular}{|l|l|l|}
\hline $\begin{array}{l}\text { Students were asked to rate the following } \\
\text { statements: }\end{array}$ & $\begin{array}{l}\text { Agree } \\
\%\end{array}$ & $\begin{array}{l}\text { Disagree } \\
\%\end{array}$ \\
\hline Creating the script was easy. & 79 & 21 \\
\hline Creating a script was enjoyable. & 84 & 16 \\
\hline $\begin{array}{l}\text { Creating a movie helped me express important } \\
\text { nuances of the conflict scenario that would have } \\
\text { been difficult in the online environment. }\end{array}$ & 97 & 3 \\
\hline I enjoyed watching movies from other groups. & 84 & 16 \\
\hline $\begin{array}{l}\text { When watching movies from other groups, the } \\
\text { movie format (i.e., visuals) helped me to } \\
\text { understand the conflict scenario. }\end{array}$ & 88 & 12 \\
\hline
\end{tabular}

After rating the statements above, learners were provided with the opportunity to respond to the following request: "Please enter any comments about movie creation and viewing." The comments regarding the experience of movie creation echoed the Likert ratings, with statements such as "I enjoyed the role-play and found it to be well thought out" and "The [backstage] chat feature was very helpful in putting the script together."

The mechanics of viewing the final movies presented some challenges, as was evidenced by comments such as "Sometimes I felt that the movies could have had a faster pace. I felt that I waited awhile until the next character spoke, etc."

Suggestions for further improvement were offered, including "Creation was ok, viewing it would be great if the movie actually read the script and the character had actual voices."

Other ideas regarding the movie compilation and viewing included, "Though the backgrounds were nice, the use of props and more realistic characters could have enhanced the movie's appeal."

Additionally, one learner proposed, "Character movement and seeing more than one character at a time." 


\section{Learning Community and Engagement}

According to the ratings for statements pertaining to the notion of a learning community, and to learner engagement, creating a movie resulted in feelings of personal accomplishment (87\%) and a sense of community with group members (83\%). Many (82\%) incorporated elements to entertain and influence movie viewers. When creating a character, 73\% agreed that they were influenced by how their classmates might perceive their character. Ninety percent agreed that peer comments and feedback on the group's movie stimulated dialogue (see Table 5).

Table 5

Role of Learning Community

\begin{tabular}{|l|l|l|}
\hline $\begin{array}{l}\text { Students were asked to rate the following } \\
\text { statements : }\end{array}$ & $\begin{array}{l}\text { Agree } \\
\%\end{array}$ & $\begin{array}{l}\text { Disagree } \\
\%\end{array}$ \\
\hline $\begin{array}{l}\text { I felt a sense of accomplishment in creating the } \\
\text { movie with my group. }\end{array}$ & 87 & 13 \\
\hline $\begin{array}{l}\text { Creating a movie helped me create a sense of } \\
\text { community with my group members. }\end{array}$ & 83 & 17 \\
\hline $\begin{array}{l}\text { When creating the script, we incorporated elements } \\
\text { to entertain and influence movie viewers. }\end{array}$ & 82 & 18 \\
\hline $\begin{array}{l}\text { When creating my character, I took into account } \\
\text { how s/ he might be perceived by my classmates. }\end{array}$ & 73 & 27 \\
\hline $\begin{array}{l}\text { Peer comments and feedback on my group's movie } \\
\text { stimulated dialogue. }\end{array}$ & 90 & 10 \\
\hline $\begin{array}{l}\text { My groups was able to work together easily using } \\
\text { Lake Devo. }\end{array}$ & 79 & 21 \\
\hline $\begin{array}{l}\text { The role of Group Leader was essential to the group } \\
\text { activity. }\end{array}$ & 82 & 18 \\
\hline
\end{tabular}

Table 6

Synchronous Collaboration

\begin{tabular}{|l|l|l|}
\hline $\begin{array}{l}\text { Students were asked to respond with a Yes or a } \\
\text { No to the following statements: }\end{array}$ & Yes & No \\
\hline $\begin{array}{l}\text { To create the script, members of my group } \\
\text { agreed on a time to log in to Lake Devo. }\end{array}$ & 79 & 21 \\
\hline $\begin{array}{l}\text { My group created the script spontaneously, } \\
\text { with little rehearsal of the actual dialogue. }\end{array}$ & 80 & 20 \\
\hline
\end{tabular}

When invited to enter any comments about working in a group and about the learning community, many learners indicated that they enjoyed the group work experience facilitated by the Lake Devo application. Their comments included: 
I found this exercise very enjoyable because of the teamwork involved, and the novelty of the method.

This was a fun and exciting exercise that added to a group learning activity which was the conflict focus of this course!

Interesting and unique way to facilitate online group learning. Some improvements could be made, but good program overall.

The majority of respondents agreed that their groups were able to arrange scripting collaboration in Lake Devo and that they authentically and spontaneously role-played (see Table 6). Nonetheless, as with many collaborative activities, some feedback was received regarding the challenges of working as a group. Some of these comments included:

It was a little frustrating communicating in Lake Devo, I found possibly just because you are working with a group of people rather than just one other person.

It was difficult to have all members meet online at the same time. The leader option was frustrating because we felt as though we couldn't accomplish very much without the group leader. It would be beneficial to free up some of the roles only the leader was allowed to do.

\section{Discussion}

As stated earlier, the Lake Devo project team set out to enhance the practice of online role-play at Ryerson through the development of a new online role-play environment. Based on the review of environments in use at the time, they deliberately designed an easy to use website, employing simple avatars, background images, and sound effects to provide multiple modes of representation in support of role-play activities. Additionally, the design allowed for the production of a movie artifact, available for review in an integrated debrief area. These design features were identified as critical to supporting the constructivist goals of role-play activity. As part of the action research approach to the project, the team collected student feedback through an online questionnaire, which produced promising findings with respect to modes of representation and the use of the movie artifact to support knowledge of the learning process. 


\section{Simple Avatars, Facial Expressions, Backgrounds, and Sound Effects as Means of Encouraging Multiple Modes of Representation}

The findings of the online questionnaire supported the idea that even simple avatars and other visual and audio elements, such as those available in the Lake Devo role-play environment, can effectively enhance and support online role-play activity. Two themes emerged from the comments of the survey participants.

Firstly, as proposed by Fabri, Moore, and Hobbs (2004) and Cornelius, Gordon, and Harris (2011), a high degree of visual realism may not be necessary in the online learning environment to engage learners in role-play activity. Based on their studies of computer games, Reeves and Nass (1996, cited in Westera, 2011) suggest that experiences which draw on limited representational and technological efforts can provoke true interpersonal responses. Such responses are clearly important in roleplays geared towards conflict resolution and negotiation. Herrington, Reeves, and Oliver (2007) examined the impact of realism in online learning environments and found that 'the 'cognitive realism' of the task is of greater importance than the reality of the task or its realistic simulation" (p. 94). Learner reactions to the pilot of the Lake Devo application echo the research in this area. As described earlier, Lake Devo was not designed to be a fully realistic world in which to interact; rather, it offers added channels of expression to support interpersonal communication. Although one learner did mention that more realistic backgrounds and props might have enhanced the movie, the overwhelming majority of participants found the simple avatars, background, and sound effects that were available during the role-play and used in the final movie to be easy to implement and helpful to their role-play activity. In the words of one learner, "The characters were pretty simplistic and I think this helps to concentrate on the actual role-play and not so much on the creation of the character."

Secondly, as put forward by Linser and Ip (2005), as cited by Russell and Shepherd (2010) and Robbins-Bell (2008), choice and customization for audio-visual elements in the application are highly valued. Redfern and Naughton (2002) suggest that avatars that are "appropriately detailed and customizable" provide a richness of expression and personality (p. 206). This notion is supported by learner comments in the survey, such as

There should be more facial features, clothing, and sound effects available when creating your character. Also, there should be more scene backgrounds; sometimes you are limited to choosing certain visuals that are not $100 \%$ correlated to your character or theme.

Redfern and Naughton (2002) claim further that customizable avatars generate interest for learners in each other's characters. As one Lake Devo participant observed, 
A wider choice of character emotions would have been more useful to portray the atmosphere (e.g., surprised, confused, etc.).

I felt as though many of the characters in our group looked very similar, therefore a little confusing. It would be nice to have more options for hair, eyes, noses, etc.

The findings of the survey, along with the literature, point to the value of simple, easy to use avatars with options for facial expressions, sound effects, and scene backgrounds, but help to underscore that greater choice in these elements would further support the role-play activity.

\section{Movie Artifact and Associated. Asynchronous Discussion Area for Debrief}

While the first area of study for this paper took into account the effectiveness of various audio-visual elements of the Lake Devo site, the second question examines the role of the multimedia component (i.e., the movie) functioning as a basis for the debrief in the associated discussion area.

Earlier, digital artifacts were outlined as beneficial in that they represent a way to record the learning event, can be shared among peers, and used for assessment purposes. More specific to visual artifacts, as opposed to text-based versions only, Perry and Edwards (2010), in their discussion of artistic pedagogical technologies, suggest that learning activities that are founded in the arts (including visual) may facilitate more authentic and meaningful social interaction between learners in an online environment. In Lake Devo, the movie as a multimedia artifact, coupled with the integrated discussion and debrief area, is especially supportive of the constructivist nature of any role-play activity. Van Ments (1999) states that there are obvious advantages to creating an audio or video record of what occurred in a role-play, including the fact that it affords learners the opportunity to study their own performance while out of role. Although the visual format in Lake Devo differs from the recording of a live performance as described by Van Ments, it can be argued that the movie plays an important role in scaffolding students' self-awareness of the knowledge construction process, by allowing for thoughtful review of the proceedings once out of role. Eighty-eight percent of participants in the Lake Devo pilot agreed that watching movies from other groups helped them to understand the conflict scenario. Furthermore, 90\% of Lake Devo pilot participants agreed that peer comments and feedback on their group's movie stimulated dialogue. While not addressed in this survey, the movie, as well as the dialogue resulting from it, could easily form the basis of learner assessment. 


\section{Limitations}

A limitation of this pilot study was the issue of technical difficulties that learners encountered, which, although resolved quickly by the DES technical support team, added frustration to the learning experience. A temporary error generated by the movie player caused one group to move their debriefing to the Blackboard LMS discussion boards. This perhaps occurred because learners and instructors were accessing the system outside of regular business hours and the technical team was unavailable to provide immediate assistance. It is believed that some learners encountered problems viewing movies, but, perhaps because they found a way to work around the problem, it was not reported until learners had the opportunity to complete the questionnaire. One participant indicated in the survey, "I had a hard time viewing the movies. I always seemed to get an error and could never view the whole movie. I had to use the arrows to fully watch the movie so no errors would come up."

\section{Implementing Findings}

Based on survey comments, the DES team has already initiated changes to the application to include more visual options for character appearance and emotions. Also the artistic style has been updated to increase the versatility in giving a unique look to learners' characters and movies based on the options they choose. The Leader role may now be exchanged among group members. The debrief area remains similar to the pilot version of the application, but further data will be collected to ensure that the design of this area optimizes the possibility of learner participation.

\section{Recommendations and Further Research}

While visual and audio options within the Lake Devo application were well received, not all aspects pertaining to modes of representation, which might impact the role-play activity and final movie, were addressed. Areas for further study include evaluating whether additional features to Lake Devo would add value, such as voice capability, enabling variety in character placement on movie backgrounds, and the ability to display props or multiple characters together on screen.

With respect to the integrated debrief area, further research is needed on the quality of postings to the discussion, as well as factors to encourage increased or optimal participation in the debrief activity.

As this study was limited to the use of the Lake Devo website in the context of only one course, additional research into the use of the site for role-play activities in other disciplines and in support of varying learning objectives may also be of value. Further testing of the Lake Devo site with a broader sampling of students certainly merits consideration given that the respondents in this study were predominantly female. 


\section{Conclusion}

A review of the current literature, together with online survey results, suggest that the Lake Devo website provides a unique alternative to text-based and/ or 3D virtual worlds as an environment that supports online role-play. The interface is intuitive and easy to use for both learners and instructors. Through the use of simple avatars, a selection of emotional expressions, and audio features, learners have the opportunity to convey nonverbal cues, which are critical to interpersonal interaction. All of these features, as supplements to the text elements, enhance the learner experience and help to support the constructivist principle of encouraging the use of multiple modes of representation. Lake Devo movies, as artifacts, along with the integrated debrief area provide an opportunity for self-awareness of the knowledge construction process. For the Lake Devo project team, whose practice is anchored in a constructivist approach, the study has encouraged a further iteration of the website, which they will continue to review, in their efforts towards continuous improvement. For practitioners beyond the Lake Devo project team and the Ryerson context, the Lake Devo website provides an example of an online role-play environment that offers alternatives to text-based and/or 3D virtual worlds. 


\section{References}

Aldrich, C. (2009). Learning online with games, simulations, and virtual worlds: Strategies for online instruction. San Francisco: J ossey Bass.

Annetta, L., Klesath, M., \& Holmes, S. (2008). V-learning: How gaming and avatars are engaging online students. Innovate: J ournal of Online Education, 4(3).

Barton, K., McKellar, P., \& Maharg, P. (2007). Authentic fictions: Simulation, professionalism and legal learning. Clinical Law Review, 14(1), 143-93.

Bell, M. (2001). Online role-play: Anonymity, engagement, and risk. Educational Media International, 38(4), 251-260.

Bender, T. (2005). Role-playing in online education: A teaching tool to enhance student engagement and sustained learning. Innovate: J ournal of Online Education, $1(4)$.

Bronack, C., Cheney, A., Riedl, R., \& Tashner, J . (2008). Designing virtual worlds to facilitate meaningful communication: Issues, considerations, and lessons learned. Technical Communication, 55(3), 261- 269.

Cornelius, S., Gordon C., \& Harris, M. (2011). Role engagement and anonymity in synchronous online role-play. International Review of Research in Open and Distance Learning, 12(5), 57- 73.

Dhaliwal, K., Gillies, M., O'Connor, J ., Oldroyd, A., Robertson, D., \& Zhang, L. (2007). eDrama: Facilitating online role-play using emotionally expressive avatars. In P. Olivier \& R. Aylett (Eds.), Proceedings of the AISB workshop on language, speech, and gesture for expressive characters. Leeds, UK: The Society for the Study of Artificial Intelligence and the Simulation of Behaviour.

Dudeney, G., \& Ramsay, H. (2009). Overcoming the entry barriers to Second Life in higher education. In C. Wankel and J . Kingsley (Eds.), Higher education in virtual worlds: Teaching and learning in Second Life (pp. 11- 28). Bingley, UK: Emerald Group Publishing Limited.

Fabri, M., Moore D., \& Hobbs D. (2004). Mediating the expression of emotion in educational collaborative virtual environments: An experimental study. Virtual Reality, 7, 66- 81.

Feinstein, A., Mann, S., \& Corsun, D. (2002). Charting the experiential territory: Clarifying definitions and uses of computer simulations, games, and role-play. J ournal of Management Development, 21(10), 732- 744. 
Finkelstein, J . (2006). Learning in real time: Synchronous teaching and learning online. San Francisco: J ossey-Bass.

Freeman, M., \& Capper, J . (1998). An anonymous asynchronous web-based role-play. Retrieved from http:// www.ascilite.org.au/conferences/wollongong98/asc98pdf/freemancapper.pdf

Gao, F., Noh, J ., \& Koehler, M. (2009) Comparing role-playing activities in Second Life and face-to-face environments. J ournal of Interactive Learning Research, 20(4), 423-443.

Herrington, J ., Reeves, T.C., \& Oliver, R. (2007) Immersive learning technologies: Realism and online authentic learning. J ournal of Computing in Higher Education, 19(1), 65-84.

Honebein, P. (1996). Seven goals for the design of constructivist learning environments. In P.G. Wilson (Ed.), Constructivist learning environments: Case studies in instructional design (pp. 11-24). Englewood Cliffs, NJ : Educational Technology Publications.

Hrastinski, S., \& Watson, J . (2009). Designing and evaluating an online role-play in conflict management. Campus-Wide Information Systems, 26(4), 287- 297.

Hughes, M., Gould, H., McKellar, P., Marharg, P., \&Nicol, E. (2008), SIMulated professional learning environment (SIMPLE) programme final report. Glasgow: University of Strathclyde.

Ingram, A., Hathorn, L., \& Evans, A. (2000). Beyond chat on the internet. Computers and Education, 35, 21- 35.

Ip, A., Linser, R., \& Naidu, S. (2001). Simulated worlds: Rapid generation of webbased role-play. Retrieved from http://ausweb.scu.edu.au/ aw01/papers/refereed/ip/.

J amaludin, A., Chee, Y., \&Ho, C. (2009). Fostering argumentative knowledge construction through enactive role-play in Second Life. Computers \& Education, 53(2), 317-329.

J ones, S. (2007). Adding value to online role-plays: Virtual situated learning environments. ICT: Providing choices for learners and learning, Proceedings Ascilite Singapore, 468-477.

Kaufman, J . (1998). Using simulation as a tool to teach about international negotiation. International Negotiation A J ournal of Theory and Practice, 3(1), 59- 75. 
Kember, D. (1998). Action research: Towards an alternative framework for educational development. Distance Education, 19(1), 43- 63.

Kinder, J ., Fardon, M., \&Yasmeen, S. (1999). Offline or online? A simulation exercise in a first-year international politics unit. In J. Winn (Ed.), Australian society for computers in learning in tertiary education conference. Brisbane, Australia: Teaching and Learning Support Services, Queensland University of Technology.

Kluge, S., \& Riley, L. (2008). Teaching in virtual worlds: Opportunities and challenges. Issues in Informing Science \& Information Technology, 5, 127- 135.

Lane, L. M. (2008). Toolbox or trap? Course management systems and pedagogy. Educause Quarterly, 31(2), 4.

Levitt, C., \&Adelman D. (2010). Role-playing in nursing theory: Engaging online students. J ournal of Nursing Education, 49(4), 229- 232.

Liebowitz, J. (2003). Teach people skills totally online? College Teaching, 51(3), 82- 85.

Lomax, P. (2007). Action research. In A. Briggs \& M. Coleman (Eds.), Research methods in educational leadership and management (pp. 156- 172). London: SAGE Publications Ltd.

McLaughlin, R., \& Kirkpatrick, D. (2004). Online role-play: Design for active learning. European J ournal of Engineering Education, 29(4), 477- 490.

Miao, M., Holst, S., Holmer, T., Fleschutz, J ., \&Zentel, P. (2000). An activity-oriented approach to visually structured knowledge epresentation for problem-based learning in virtual learning environments. In R. Dieng, A. Giboin, L. Karsenty, \& G. De Michelis (Eds.), Designing cooperative systems: The use of theories and models (pp. 303- 318). Amsterdam, Netherlands: IOS Press.

Morse, S., Littleton, F., Macleod, M., \& Ewins, R. (2009). The theatre of performance appraisal: Role-play in Second Life. In C. Wankel \&J . Kingsley (Eds.), Higher education in virtual worlds: Teaching and learning in Second Life (pp. 181201). Bingley, UK: Emerald Group Publishing Limited.

Moser, F. Z. (2007). Faculty adoption of educational technology. EDUCAUSE Quarterly, 30(1), 66.

Nelson, D., \& Blenkin, C. (2007). The power of online role-play simulations: Technology in nursing education. International J ournal of Nursing Education Scholarship, 4(1), 1- 12 .

Perry, B., \&Edwards, M. (2010). Creating a culture of community in the online classroom using artistic pedagogical technologies. In B. Veletsianos (Ed.), 
Emerging technologies in distance education (pp. 129- 152). Athabasca, AB: Athabasca University Press.

Peterson, M. (2006). Learner interaction management in an avatar and chat-based virtual world. Computer Assisted Language and Learning, 19(1), 79- 103.

Phillips, J . (2005). Chat role-play as an online learning strategy. J ournal of Nursing Education, 44(1), p. 43.

Redfern, R., \&Naughton, N. (2002). Collaborative virtual environments to support communication and community in internet-based distance education. J ournal of Information Technology Education, 1(3), 201- 211.

Robbins-Bell, S. (2008). Higher education as virtual conversation. EDUCAUSE Review, 43(5), 24- 35.

Russell, C., \& Shepherd, J . (2010). Online role-play environments for higher education. British J ournal of Educational Technology, 41(6), 992- 1002.

Starkey, B., \& Blake, L. (2001). Simulation in international relations education. Simulation \& Gaming, 32(4), 537-551.

Van Ments, M. (1999). The effective use of role-play: A handbook for teachers and trainers ( $2^{\text {nd }}$ ed.). London: Kogan Page Ltd.

Vavrina, V. (1992). From Poughkeepsie to Peoria to the Persian Gulf: A novice's ICONS odyssey. PS: Political Science and Politics, 25(4), 700- 702.

Vincent, A., \& Shepherd, J . (1998). Experiences in teaching Middle East politics via internet-based role-play simulations. J ournal of Interactive Media in Education, 98(11).

Warburton, S. (2009). Second Life in higher education: Assessing the potential for and the barriers to deploying virtual worlds in learning and teaching. British J ournal of Educational Technology, 40(3), 414-426.

Westera, W. (2011). On the changing nature of learning context: Anticipating the virtual extensions of the world. J ournal of Educational Technology \& Society, 14(2), 201-- 212 .

Wills, S., \& McDougall, A. (2009). Reusability of online role play as learning objects or learning designs. In L. Lockyer, S. Bennett, S. Agostinho \& B. Harper (Eds.), Handbook of research on learning design and learning objects: Issues, applications and technologies (Vol. 2, pp. 761- 776). Hershey, PA: Information Science Reference. 


\section{Athabasca University $\mathbf{a}$}

(c)

